\title{
FEATURES OF COMMISSION AND PRODUCTION OF CERTAIN TYPES OF FORENSIC EXAMINATIONS (ENVIRONMENTAL ASPECT)
}

\author{
Olga A. Yakovleva \\ Volgograd State University, Volgograd, Russian Federation
}

Introduction: it is difficult to overestimate the importance of forensic examination in the investigation of crimes. Almost every criminal act cannot be solved without a certain expertise. The questions posed to the experts are diverse and depend on the subject of the expert study. As for the public authorities and various public organizations, the expertise is important for them, first of all, in the context of solving those issues that affect the interests of both the individual and the state as a whole. The possibilities of studying the object determine the tasks facing the forensic expert. The aim of the research is to analyze the issues related to the features of commission and production of certain types of forensic examinations. Methods: the methodological framework for this study includes a set of methods of scientific knowledge, among which the fundamental importance is given to the methods of system analysis, synthesis. Results: the importance of the examination before the initiation of a criminal case is determined, and the emphasis is placed on the need for the correct formulation of questions for the expert. Conclusions: in legal science there is a point of view, according to which the obligation to prove the circumstances of the case can be completely shifted by judges and investigators onto forensic experts, what is the danger of expertise. In the author's opinion, in many cases it is not possible to establish the event of the crime, the severity of the crime, as well as the damage caused, without conducting special expert studies.

Key words: expertise, expert, crime, investigator, investigation.

Citation. Yakovleva O.A. Features of Commission and Production of Certain Types of Forensic Examinations (Environmental Aspect). Legal Concept, 2019, vol. 18, no. 2, pp. 134-138. (in Russian). DOI: https://doi.org/10.15688/ lc.jvolsu.2019.2.22

\section{ОСОБЕННОСТИ НАЗНАЧЕНИЯ И ПРОИЗВОДСТВА ОТДЕЛЬНЫХ ВИДОВ СУДЕБНЫХ ЭКСПЕРТИЗ (ЭКОЛОГИЧЕСКИЙ АСПЕКТ)}

\author{
Ольга Алексеевна Яковлева \\ Волгоградский государственный университет, г. Волгоград, Российская Федерация
}

Введение: сложно переоценить роль судебной экспертизы при расследовании преступлений. Почти каждое преступное деяние не представляется возможным раскрыть без проведения определенной экспертизы. Вопросы, которые ставятся перед экспертами, разнообразны и зависят от предмета экспертного исследования. Что касается органов государственной власти, а также различных общественных организаций, то для них экспертиза важна, прежде всего, в контексте решения тех вопросов, которые затрагивают интересы как отдельного гражданина, так и государства в целом. Возможности исследования объекта определяют задачи, которые стоят перед судебным экспертом.

В работе поставлена цель - проанализировать вопросы, касающиеся особенностей назначения и производства отдельных видов судебных экспертиз. Методы: в методологическую основу данного исследования входит целый комплекс методов научного познания, среди которых основополагающее значение отведено методу системного анализа, синтеза. Результаты: определена значимость производства экспертиз до воз(2) буждения уголовного дела, а также сделан акцент на необходимость правильного формулирования вопро- 
сов для эксперта. Выводы: в науке существует точка зрения, согласно которой обязанность доказывания обстоятельств дела может быть полностью переложена судьями и следователями на судебных экспертов, в чем заключается опасность экспертиз. По нашему мнению, во многих случаях не представляется возможным установить событие преступления, степень тяжести содеянного, а также нанесенный ущерб, не проводя специальных экспертных исследований.

Ключевые слова: экспертиза, эксперт, преступление, следователь, расследование.

Цитирование. Яковлева О. А. Особенности назначения и производства отдельных видов судебных экспертиз (экологический аспект) // Legal Concept = Правовая парадигма. - 2019. - T. 18, № 2. - C. 134-138. - DOI: https://doi.org/10.15688/lc.jvolsu.2019.2.22

\section{Введение}

Общеизвестным является то, что установить признаки любого преступления возможно лишь при наличии конкретных фактических обстоятельств. Полагаем, причинная связь между фактом нарушения экологических правил и наступившими вредными последствиями должна быть включена в предмет рассмотрения на стадии возбуждения уголовного дела. Только эксперт может установить факт нарушения экологических правил (определить масштаб превышения ПДК, состав загрязняющего вещества и т. д.).

В науке долгое время являлись дискуссионными и до сих пор остаются такие вопросы, как понятие предмета судебной экспертизы [4, с. 126-127; 14, с. 37; 13, с. 25], производство повторных и альтернативных экспертиз [3, с. 76-81; 10, с. 121-122; 16, с. 85-86], соотношение заключения эксперта и заключения специалиста, производство экспертиз до возбуждения уголовного дела и др.

В силу специфики указанных обстоятельств требуется при проведении экспертизы привлечение специалистов, обладающих соответствующими познаниями в рамках своего узкого профиля - экологи, зоологи, метеорологи, ихтиологи, почвоведы, агротехники и др.

Многие исследователи солидарны в необходимости проведения экспертизы в требующих того случаях $[9$, с. $21-22 ; 8$, с. $33 ; 1$, с. $117-118 ; 2$, с. $19 ; 7$, с. 6-7; 6, с. 131-132]. Полагаем, применительно к экологическим преступлениям проведение экспертизы всей материальной обстановки является важным этапом расследования.

В науке является распространенным мнение о «типичных судебных экспертизах», которые часто проводятся при расследованиях [12, с. 26; 5, с. 187]. Типичность в данном случае связана со спецификой и методикой расследования.

\section{Классификация экспертиз, назначаемых в процессе расследования экологических преступлений}

Рассмотрим классификацию экспертиз, предложенную А.П. Резван и использованную в нашем исследовании (см. рисунок). В ее основе лежит признак разделения экспертиз по предмету исследования [17, с. 14-15].

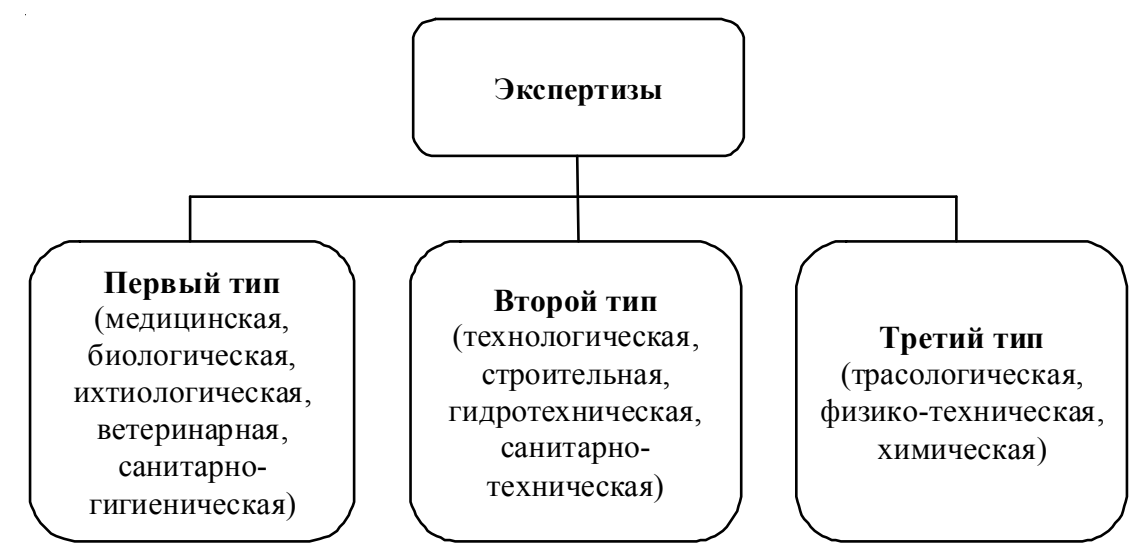

Экспертизы, назначаемые в процессе расследования экологических преступлений 
По нашему мнению, достоинство представленной классификации заключается в том, что она является наиболее полной.

Судебно-экологическую экспертизу назначают при расследовании преступлений, где произошло нарушение правил охраны окружающей среды при производстве работ. Там, где вопросы касаются природоохранной деятельности, привлекают различных экспертов: химиков, биологов и др. [15, с. 110]. В случае, если было нарушено законодательство о производстве экологической экспертизы на стадии планирования работ, по данному факту назначают судебную экологическую экспертизу. Последняя должна установить наличие проектной документации, заключений с выводами ведомственных экспертиз, документов, подтверждающих предварительное обсуждение вопроса о строительстве объекта. В заключении данной экспертизы должен быть указан уровень загрязнения, а также причины, которые вызвали экологический вред.

Судебно-медицинскую экспертизу назначают в тех случаях, когда был причинен вред здоровью человека. Анализируемую экспертизу проводят также после завершения преступного деяния, когда уже проявляются последствия преступления при изучении следователем истории болезней потерпевших.

\section{Формулирование вопросов для разрешения экспертом}

Необходимо подчеркнуть, что от правильности поставленных перед экспертом вопросов зависит полнота сведений о характере причиненного вреда, связи между наступившими последствиями и деянием, а также других признаках преступления. Однако, как показывает практика, зачастую в вопросах, которые формулирует следователь в постановлении о назначении экспертизы, неверно определен объект исследования, в то время как верно сформулированные вопросы могут значительно помочь в расследовании преступления.

К примеру, в постановлении о назначении биологической судебной экспертизы по факту загрязнения водоема и уничтожения ценных пород рыб при производстве работ вопросы, которые будут поставлены перед экспертом, позволят определить степень вреда, причиненного биоресурсам, его характер, а также то, возможно ли этот вред оценить в денежном эквиваленте. Эксперту необходимо дать ответы на вопросы:

1. В чем выражен вред, причиненный биоресурсам рыбохозяйственного водоема?

2. Подлежит ли причиненный рыбохозяйственному водоему вред денежной оценке?

3. Какой вред причинен рыбным ресурсам (молоди, личинкам, икре)?

4. Какой вред причинен кормовым организмам и потомству, ожидающемуся от половозрелых рыб, морского зверя и других гидробионтов?

5. Имеются ли условия ухудшения обитания и воспроизводства рыб и других животных ресурсов водоема?

6. Имеются ли нарушения естественной миграции рыб и других гидробионтов? Если да, то какой вред причинен растительности и какой вред причинен лесным землям?

7. Если биоресурсам причинен вред в результате выполнения работ, то является ли ущерб значительным и невосполнимым?

Данные вопросы помогают детализировать причиненный вред. Более того, вопросы способствуют правильному решению диагностических и ситуационных задач, а также при судебной экспертизе. Чем логичнее будет поставлен вопрос, тем последовательнее будут рассмотрены обстоятельства преступления, следовательно, станет возможным установить обстоятельства, начиная с момента нарушения экологических правил, заканчивая вредными последствиями.

В случае, если превышены нормы ПДВ и известна информация об источнике загрязнения, эксперт должен определить возможность загрязнения природных объектов при погодных условиях, наблюдающихся в момент выброса вредных веществ. Постановка таких вопросов будет способствовать выявлению вредного воздействия.

Для производства судебной экспертизы эксперту требуются материалы дела, которыми выступают: протоколы следственных действий, заключения других экспертов и иные документы от организаций (справки, акты, запросы), которые обеспечат полноту и достоверность исследования. 


\section{Выводы}

В науке существует точка зрения, согласно которой обязанность доказывания обстоятельств дела может быть полностью переложена судьями и следователями на судебных экспертов, в чем заключается опасность экспертиз [11, с. 37]. Полагаем, во многих случаях проведение специальных экспертных исследований является неотъемлемой частью в расследовании преступлений.

\section{СПИСОК ЛИТЕРАТУРЫ}

1. Ароцкер, Л. Е. Использование данных криминалистики в судебном разбирательстве уголовных дел / Л. Е. Ароцкер. - М. : Юрид. лит. 1964. - 120 с.

2. Белкин, Р. С. Криминалистическая экспертиза на месте происшествия / Р. С. Белкин // Теория и практика криминалистической экспертизы. - Волгоград: НИиРИО ВСШ МВД СССР, 1980. - С. 16-27.

3. Бондаренко, П. В. Повторные, «параллельные» экспертизы и экспертизы экспертиз / П. В. Бондаренко // Вестник криминалистики. - 2004. - Вып. 3 (11). - C. 76-81.

4. Винберг, А. И. Судебная экспертология (общетеоретические и методологические основы судебной экспертизы) / А. И. Винберг, Н. Т. Малаховская. Волгоград : Изд-во ВСШ МВД СССР, 1979. - 181 с.

5. Гавриш, С. Б. Экологические преступления: квалификация и методика расследования / С. Б. Гавриш, В. Г. Грузкова, А. Л. Дудников. - Харьков : Глобус, 1994. - $226 \mathrm{c.}$

6. Гончаренко, В. И. Использование данных естественных и технических наук в уголовном судопроизводстве / В. И. Гончаренко. - Киев : Вища школа, $1980 .-160 \mathrm{c}$.

7. Грановский, Г. Л. Криминалистическая ситуационная экспертиза места происшествия / Г. Л. Грановский // Рефераты научных сообщений. - М. : Изд-во ВНИИСЭ, 1977. - Вып. 16. - С. 3-16.

8. Зуйков, Г. Г. Установление способа совершения преступления / Г. Г. Зуйков. - М. : Изд-во ВШ МВД СССР, 1970. $-45 \mathrm{c}$.

9. Комаринец, Б. М. Участие экспертов-криминалистов в проведении следственных действий по особо опасным преступлениям против личности / Б. М. Комаринец// Теория и практика судебной экспертизы. Сб. 1 (2). - М. : Юрид. лит., 1964. - С. 6-64.

10. Костенко, Р. В. Проблемы реализации права собирать и представлять доказательства участниками уголовного судопроизводства / Р. В. Костенко // Правовая парадигма. - 2018. - Т. 17, № 2. C. 119-125.
11. Кудрявцева, А. Доказательственное значение «правовых экспертиз» в уголовном процессе / А. Кудрявцева // Российская юстиция. - 2003. № 1. - C. 36-38.

12. Матусовский, Г. А. Методика расследования хищений / Г. А. Матусовский. - Киев : Вища шк., 1988. -405 с.

13. Мирский, Д. Я. Понятие объекта судебной экспертизы / Д. Я. Мирский, М. Н. Ростов // Актуальные проблемы теории судебной экспертизы. М. : Изд-во ВНИИСЭ, 1984. - С. 21-33.

14. Надгорный, Г. М. Предмет судебно-экспертной отрасли знания и предмет судебной экспертизы / Г. М. Надгорный // Криминалистика и судебная экспертиза. - 1976. - Вып. 13. - С. 37-43.

15. Основы эколого-географической экспертизы / под ред. К. Н. Дьяконова, Т. В. Звонковой. - М. : Изд-во МГУ, 1992. - 234 с.

16. Разгельдеев, Н. Т. Правовые проблемы обеспечения дачи объективных экспертных заключений экологической безопасности Российской Федерации / Н. Т. Разгельдеев, Т. А. Максимова // Правовые институты и методы охраны окружающей среды в России, странах СНГ и европейского союза: состояние и эффективность. - Саратов : Саратовский источник, 2017. -249 с.

17. Резван, А. П. Теоретические вопросы подготовки и назначения экспертиз по делам об охране природы : автореф. дис. ... канд. юрид. наук / Резван Александр Павлович. - М., 1980. - 16 с.

\section{REFERENCES}

1. Arocker L.E.Using Forensic Data in Criminal Proceedings. Moscow, Jurid. lit. Publ., 1964. 120 p. (in Russian).

2. Belkin R.S. Forensic Expertise at the Scene. Theory and Practice of Forensic Examination. Volgograd, NIiRIO VSSh MVD SSSR, 1980, pp. 16-27.

3. Bondarenko P.V. Repeated, "Parallel" Examinations and Expert Examinations. Vestnik kriminalistiki, 2004, no. 3 (11), pp. 76-81. (in Russian).

4. Vinberg A.I., Malakhovskaya N.T. Judicial Expertology (General Theoretical and Methodological Foundations of Forensic Examination). Volgograd, Izd-vo VSSh MVD SSSR, 1979. 181 p. (in Russian).

5. Gavrish S.B., Gruzkova V.G., Dudnikov A.A. Environmental Crimes: Qualifications and Investigation Techniques. Kharkov, Globus Publ., 1994. 226p. (in Russian).

6. Goncharenko V.I. The Use of Data of Natural and Technical Sciences in Criminal Proceedings. Kiev, Vishha shk. Publ., 1980. 160 p. (in Russian).

7. Granovskij G.L. Forensic Situational Examination of the Scene. Referaty nauchnyh soobshhenij. Moscow, Izd-vo VNIISJe, 1977, no. 16, pp. 3-16. (in Russian). 


\section{ПРОЦЕССУАЛЬНОЕ ПРАВО: ВОПРОСЫ ТЕОРИИ И ПРАВОПРИМЕНЕНИЯ}

8. Zujkov G.G. Establishing the Method of Committing a Crime. Moscow, Izd-vo VSh MVD SSSR, 1970. 45 p. (in Russian).

9. Komarinec B.M. Participation of Forensic Experts in the Conduct of Investigative Actions for Especially Dangerous Crimes Against the Person. Teorija i praktika sudebnoj jekspertizy, Sb. 1 (2), Moscow, 1964,pp. 6-64. (in Russian).

10. Kostenko R.V. Participation of Forensic Experts in the Conduct of Investigative Actions for Especially Dangerous Crimes Against the Person. Pravovaya paradigma, 2018, vol. 17, no. 2, pp. 119-125. (in Russian).

11. Kudrjavceva A. Evidentiary Value of "Legal Expertise" in Criminal Proceedings. Rossijskajajusticija, 2003, no. 1, pp. 36-38. (in Russian).

12. Matusovskij G.A. Theft Investigation Technique. Kiev, Vishha shk. Publ.,1988.405 p. (in Russian).

13. Mirskij D.Ja. The Concept of the Object of Forensic Examination. Actual Problems of the Theory of Forensic Examination. Moscow, Izd-vo VNIISJe, 1984, pp. 21-33. (in Russian).

14. Nadgornyj G.M. The Subject of Forensic Industry Knowledge and the Subject of Forensic Examination. Kriminalistika i sudebnaja jekspertiza. Kiev, Vishha shk. Publ., 1976, no. 13,pp. 37-43. (in Russian). 15. Djakonova K.N., Zvonkovoj T.V., eds. Fundamentals of Ecological and Geographical Expertise. Moscow, Izd-vo MGU, 1992.234 p. (in Russian).

16. Razgeldeev N.T., Maksimova T.A. Legal Problems of Ensuring the Giving of Objective Expert Opinions of the Environmental Safety of the Russian Federation. Pravovye instituty i metody ohrany okruzhayushchej sredy v Rossii, stranah SNG $i$ evropejskogo soyuza: sostoyanie i ehffektivnost. Saratov, Saratovskij istochnik Publ., 2017. 249 p. (in Russian).

17. Rezvan A.P. Theoretical Issues of Preparation and Appointment of Examinations in Cases of Environmental Protection. Cand. jurid. sci. diss. Moscow, 1980. 16 p. (in Russian).

\section{Information about the Author}

Olga A. Yakovleva, Candidate of Sciences (Jurisprudence), Associate Professor, Department of Criminal Law, Volgograd State University, Prosp. Universitetsky, 100, 400062 Volgograd, Russian Federation, olgayakovlev@mail.ru, https://orcid.ord/0000-0002-6833-5005

\section{Информация об авторе}

Ольга Алексеевна Яковлева, кандидат юридических наук, доцент кафедры уголовного права, Волгоградский государственный университет, просп. Университетский, 100, 400062 г. Волгоград, Российская Федерация, olgayakovlev@mail.ru, https://orcid.ord/0000-0002-6833-5005 